S5 Table. In silico predictive algorithms used in the study [3].

\begin{tabular}{|c|c|c|c|c|}
\hline Category & Basis & Name & Website & Prediction Threshold \\
\hline \multirow[t]{2}{*}{ Missense prediction } & \multirow[t]{2}{*}{ Evolutionary conservation } & FATHMM & http://fathmm.biocompute.org.uk & $\begin{array}{l}<-1.5 \text { Damaging } \\
>-1.5 \text { Tolerated }\end{array}$ \\
\hline & & SIFT & http://sift.jcvi.org & $\begin{array}{l}<0.05 \text { Deleterious } \\
>0.05 \text { Tolerated }\end{array}$ \\
\hline \multirow[t]{3}{*}{ Missense prediction } & \multirow[t]{3}{*}{$\begin{array}{l}\text { Protein structure/function and } \\
\text { evolutionary conservation }\end{array}$} & Align GVGD & $\begin{array}{l}\text { http://agvgd.iarc.fr/agvgd_input. } \\
\text { php }\end{array}$ & $\geqq \mathrm{C} 15$ Probably Damaging \\
\hline & & $\begin{array}{l}\text { Mutation } \\
\text { Taster }\end{array}$ & http://www.mutationtaster.org & Disease causing \\
\hline & & Polyphen-2 & $\begin{array}{l}\text { http://genetics.bwh.harvard.edu/ } \\
\text { pph2 }\end{array}$ & $\begin{array}{l}0.85 \text { to } 1 \text { Probably Damage } \\
0.15 \text { to } 0.85 \text { Possibly } \\
\text { Damage }\end{array}$ \\
\hline $\begin{array}{l}\text { Missense } \\
\text { insertion/deletions } \\
\text { prediction }\end{array}$ & $\begin{array}{l}\text { Alignment and measurement of } \\
\text { similarity between variant sequence } \\
\text { and protein sequence homolog }\end{array}$ & PROVEAN & http://provean.jcvi.org/index.php & $\begin{array}{l}<-2.5 \text { Deleterious } \\
>-2.5 \text { Neutral }\end{array}$ \\
\hline $\begin{array}{l}\text { Missense } \\
\text { insertion/deletions } \\
\text { prediction }\end{array}$ & $\begin{array}{l}\text { Contrasts annotations of fixed/nearly } \\
\text { fixed derived alleles in humans with } \\
\text { simulated variants }\end{array}$ & CADD & http://cadd.gs.washington.edu & $\begin{array}{l}\geqq 20 \quad 1 \% \text { most deleterious } \\
\geqq 30 \quad 0.1 \% \quad \text { most } \\
\text { deleterious }\end{array}$ \\
\hline
\end{tabular}

\title{
Supporting Reference
}

3. Richards S, Aziz N, Bale S, Bick D, Das S, Gastier-Foster J, Grody WW, Hegde M, Lyon E, Spector E, Voelkerding K, Rehm HL. Standards and guidelines for the interpretation of sequence variants: a joint consensus recommendation of the American College of Medical Genetics and Genomics and the association for molecular autopsy. Genet Med. 2015; 17: 405-423. 